\title{
Preparation and Bactericidal Effect of Composites Based on Crosslinked Copolymers Containing Silver Nanoparticles
}

\author{
Luiz C. de Santa Maria, Rachel 0. Oliveira, Fabio Merçon \\ Instituto de Química, UERJ
}

\author{
Maria E. R. S. P. Borges \\ Instituto de Biociências, UNIRIO
}

\author{
Hernane S. Barud, Sidney J. L. Ribeiro, Younés Messaddeq \\ Instituto de Química, UNESP
}

Shu H. Wang

Departamento de Engenharia Metalúrgica e de Materiais, USP

\begin{abstract}
Commercial copolymers based on styrene and divinylbenzene containing sulfonic acid groups were used as support for the incorporation of silver nanoparticles. These nanoparticles were obtained in situ by the reduction of $\mathrm{Ag}^{+}$by using hydroxylamine in the presence of a protective agent. These materials were characterized with determination of the silver content and their morphological characteristics. The antibacterial activity of the final products against Escherichia coli was evaluated and the results show that the synthesized copolymers had antibacterial effect varying from 54 to $100 \%$. The most efficient composite was made with small, well distributed particles.
\end{abstract}

Keywords: Nanocomposite, silver, copolymer, resin.

\section{Introduction}

Contamination of water by bacteria can cause many waterborne diseases, such as dysentery and cholera ${ }^{[1]}$. Important sources of this contamination are urban sewage and industrial effluents. Sewage contamination is usually identified by the presence of fecal coliforms.

Escherichia coli is a bacterium belonging to the coliform group and to the family enterobacteriaceae $e^{[2]}$. Typical untreated domestic wastewater usually contains from $10^{6}$ to $10^{9}$ total coliforms per $100 \mathrm{~mL}$, according to the wastewater pollution level ${ }^{[3]}$. This bacterium has been detected in food and drinking water ${ }^{[4]}$. To avoid levels harmful to human health and well-being, efficient water purification is necessary. This procedure allows the recycling of water without harming human health and the environment.

Silver nanoparticles have shown high antibacterial effect against several species of harmful bacteria ${ }^{[5]}$. They have been used not only against environmental problems but also in the textile industry ${ }^{[6]}$ and for medical applications ${ }^{[7]}$. The qualities of silver in addition to the polymer morphology provide some features that give copolymers containing silver nanoparticles advantages over traditional techniques used to disinfect water, such as chlorination, use of antibiotics and ozonization ${ }^{[8]}$. The non-formation of byproducts, absence of cross-resistance, material stability and possibility of recycling are some of these features ${ }^{[9]}$.

This paper deals with the synthesis, characterization and evaluation of four different composites containing silver nanoparticles, obtained from the modification of two commercial copolymers, for disinfection of water contaminated by bacteria. Our goal is to study the influence of these composites' characteristics on the capability of reducing the number of viable Escherichia coli cells.

\section{Experimental Part}

\section{Incorporation of silver in the copolymers}

First, the commercial resins were activated by treatment in an acid solution. About $10 \mathrm{~g}$ of each commercial copolymer - Lewatit ${ }^{\circledR}$ VPOC1800 (sulfonated copolymer based on styrene and divinylbenzene, from Bayer Co.) and Amberlyst ${ }^{\circledR}$ 15WET (sulfonated copolymer based on styrene and divinylbenzene, from Rohm and Haas Co.) - were placed in $2 \%$ v/v aqueous solution of $\mathrm{HCl}$ for 48 hours. Then the resins were filtered out and washed thoroughly with distilled and deionized water in order to reach a $\mathrm{pH}$ close to neutral. The resins were thoroughly rinsed with portions of $95 \%$ ethanol and dried at $60{ }^{\circ} \mathrm{C}$ for 24 hours.

The acid resins were immersed in $100 \mathrm{~mL}$ of $2 \% \mathrm{w} / \mathrm{v} \mathrm{AgNO}_{3}$ solution and acidified with 2 drops of $\mathrm{HNO}_{3}$ for 48 hours. The impregnated resins were filtered off and washed with cold distilled and deionized water until the $\mathrm{AgCl}$ precipitate disappeared in the $\mathrm{NaCl}$ aqueous solution.

\section{Reduction reaction of $\mathrm{Ag}^{+}$ions}

For each impregnated resin the following procedures were performed: Two solutions of gelatin and 2-hydroxy-ethyl cellulose at $0.6 \% \mathrm{w} / \mathrm{v}$ at proportion of $1: 1$ were prepared and cooled in an ice bath. The resin was added to one of these solutions and in the other $3 \mathrm{~g}$ of hydroxylamine chloride was added. The $\mathrm{pH}$ was controlled by adding drops of a 2 mol. $\mathrm{L}^{-1}$ solution of $\mathrm{NaOH}$ or $\mathrm{NH}_{4} \mathrm{OH}$ to keep the $\mathrm{pH}$ at approximately 12 . The hydroxylamine chloride solution was added to the resin solution during 20 minutes. After that, the solution was left at rest for 10 minutes in an ice bath and 25 minutes at $25^{\circ} \mathrm{C}$. The resins were then washed with distilled and deionized water at $60{ }^{\circ} \mathrm{C}$.

Autor para correspondência: Luiz C. de S. Maria, Instituto de Química, Universidade do Estado do Rio de Janeiro, Rua São Francisco Xavier, 524, 
The two commercial resins and the two different solutions used for $\mathrm{pH}$ control $\left(\mathrm{S}_{\mathrm{pH}}\right)$ resulted in four distinct composites at the end of each reaction: VPOC1 $\left(\mathrm{S}_{\mathrm{pH}} \mathrm{NaOH}\right)$; VPOC2 $\left(\mathrm{S}_{\mathrm{pH}} \mathrm{NH}_{4} \mathrm{OH}\right)$; $\mathrm{WET} 1\left(\mathrm{~S}_{\mathrm{pH}} \mathrm{NaOH}\right)$; and WET2 $\left(\mathrm{S}_{\mathrm{pH}} \mathrm{NH}_{4} \mathrm{OH}\right)$.

\section{Characterization of the composites}

The characterization of the copolymers was determined by nitrogen adsorption data obtained with a Micromeritcs surface area and porosity analyzer (ASAP). The ASAP was employed to compare the surface area before and after the silver incorporation.

The resin's appearance and morphology as well as the silver particles obtained were evaluated with a Philips model XL-30 scanning electron microscope (SEM) equipped with a backscattered electron detector (BSE). The acceleration voltage was $20 \mathrm{kV}$. An energy dispersive $\mathrm{X}$ ray spectrometry (EDS) microprobe from EDAX Co. was used to confirm the silver presence.

The silver content of the composites was measured by a Shimadzu EDX-800HS energy dispersive $\mathrm{X}$ ray fluorescence spectrometer (EDXRF) equipped with a liquid nitrogen cooled $\mathrm{Si}$ (Li) detector.

\section{Antibacterial analyses}

The purpose of the antibacterial analyses was to evaluate the synthesized copolymers' ability to reduce the number of viable cells. The test was conducted in triplicate with a suspension of $E$. coli $\left(\right.$ ATCC $^{\circledR} 25922^{\mathrm{TM}}$ ) using the viable plate count method described by Jandrey et al. ${ }^{[10]}$. The E. coli strains were cultured in lauryl sulphate tryptose broth for 18 hours at $37^{\circ} \mathrm{C}$ beforehand. Successive dilution of the E. coli solution was performed with sterile $\mathrm{NaCl}$ aqueous solution at $0.9 \% \mathrm{w} / \mathrm{v}$ in order to obtain concentrations from $10^{3}$ to $10^{7}$ cells. $\mathrm{mL}^{-1}$. All solutions from $10^{4}$ to $10^{7}$ were diluted with saline to reach concentrations equal to $10^{3}$ thus facilitating the counting of plates after elution. The different $E$. coli solutions were conducted through columns containing $0.2 \mathrm{~mL}$ of each copolymer. The original copolymers without silver added were also tested. All copolymers were neutralized with $2 \% \mathrm{w} / \mathrm{v}$ of $\mathrm{NaHCO}_{3}$ solution to prevent the possible influence of acid groups. After passing through the column, the solutions were placed in eosin/methylene blue Levine agar plates and incubated at $37^{\circ} \mathrm{C}$ for 48 hours to count the colonies. As control, the same procedure was performed with the same E. coli solutions without passing them through the column. A CP600 Phoenix 617 colony counter was used to measure the colony forming unit (CFU) in each plate. The percentage reduction in bacterial count was calculated by the Equation 1.

Equation 1: The percentage reduction in bacterial count ${ }^{[11]}$.

$$
R_{p}=\left[\frac{\left(C_{b}-C_{a}\right)}{C_{b}}\right] \times 100 \%
$$

where:

$\mathrm{R}_{\mathrm{p}}=$ percentage reduction;

$\mathrm{C}_{\mathrm{b}}^{\mathrm{p}}=$ viable count before column;

$\mathrm{C}_{\mathrm{a}}=$ viable count after column.

The statistical analysis was performed using Student's $t$-test ${ }^{[12]}$.

\section{Results and Discussion}

The ASAP results of the copolymers are listed in Table 1 .

Although both resins used have the same polymer base and functional group, the morphology of each has distinct characteristics. The Lewatit ${ }^{\circledR}$ VPOC1800 is a gel-like resin ${ }^{[13]}$ while the Amberlyst ${ }^{\circledR}$ $15 \mathrm{WET}$ is a macroreticular resin with high porosity.

The values of surface area were lower for all the composites synthesized compared to the respective polymer matrix. This behavior can be attributed to presence and agglomeration of silver particles within the pores and channels, resulting in a decrease of open spaces and its consequent non-measuring ${ }^{[14]}$. One of the factors that determine the size of the silver particles is the pore size of the resin, since this space is a physical barrier that prevents agglomeration of particles, serving as template. Macroporous resins showed an increase in pore diameter with addition of silver. This result can be explained by a possible strain of the pores wall generated by the presence of the particle in their interior ${ }^{[15]}$. However, the resin gel had the opposite trend, possibly in this case the particles were not able to extend the pore of the polymer matrix diminishing the pore size because of its partial filling.

The SEM images showed a significant difference among the four composites. Non-uniform coarse precipitation was observed in VPOC1 (Figure 1a) while the composite VPOC2 (Figure 1b) had narrow size distribution of the silver particles. Thus, the agglomeration of the particles was considerably greater in the VPOC1 in comparison with the VPOC2 composite. The composite WET1 (Figure 1c) had a more homogeneous distribution but larger particle sizes than the WET2 composite (Figure 1d).

The EDS confirmed the formation of elemental silver in all composites (Figure 1a, 1b, 1c and 1d). However, the silver content varied greatly. This result was confirmed by EDXRF, which technique the total amount of silver is calculated as the proportion of silver oxides found per $\mathrm{mm}^{2}$ of sample. The following percentages were found: $\mathrm{VPOC} 1=7.9 \%$; VPOC $2=9.6 \%$; WET $1=44.9 \%$; and $\mathrm{WET} 2=23.1 \%$.

The $\mathrm{NH}_{4} \mathrm{OH}$ solution used for $\mathrm{pH}$ control optimized the formation of smaller silver particles than in those controlled with $\mathrm{NaOH}$ solution. It can be explained by a possibly stronger reaction control through the formation of an $\left[\mathrm{Ag}\left(\mathrm{NH}_{3}\right)_{2}\right]^{+}$complex by the $\mathrm{NH}_{4} \mathrm{OH}$ while the $\mathrm{NaOH}$ solution favors the formation of silver clusters in the polymer surface ${ }^{[16]}$. The Figure 2 shows two possible nanosilver formations.

\section{Antibacterial analyses}

The efficacy of the copolymers containing silver nanoparticles against $E$. coli was measured by the viable plate count method. The results are presented as average values over all dilutions in Table 2.

After 48 hours of incubation, the viable $E$. coli declined by 54 and $100 \%$, according to the composite. There was no reduction in viable counts in the control group and also in the solution that was eluted through the column without silver.

The most efficient antimicrobial copolymer against $E$. coli was VPOC2. This result indicates that the silver content does not seem to be closely related to the bactericide effect since this copolymer did not contain high levels of silver. VPOC2 composite had smaller particles with higher specific surface area and narrower size distribution than the other composites. The combination of these parameters produced 100\% antimicrobial efficiency. Despite WET1 presents larger particles than WET2, its distribution in the polymer was homogeneous all through the polymer favoring the interaction between silver and bacteria. These results may explain the similar bactericidal activity of both composites.

Table 1. Characterization of porosity and surface area.

\begin{tabular}{lcc}
\hline \multicolumn{1}{c}{ Copolymers } & Pore size $(\AA)$ & Surface area $\left(\mathbf{m}^{2} \cdot \mathbf{g}^{-1}\right)$ \\
\hline Lewatit ${ }^{\circledast}$ VPOC1800 & 21.6 & 3.0 \\
VPOC1 & $*$ & $*$ \\
VPOC2 & $*$ & $*$ \\
Amberlyst ${ }^{\boxplus}$ 15WET & 234.9 & 54.7 \\
WET1 & 242.7 & 35.8 \\
WET2 & 251.9 & 36.4 \\
\hline
\end{tabular}

*below the detection limit 


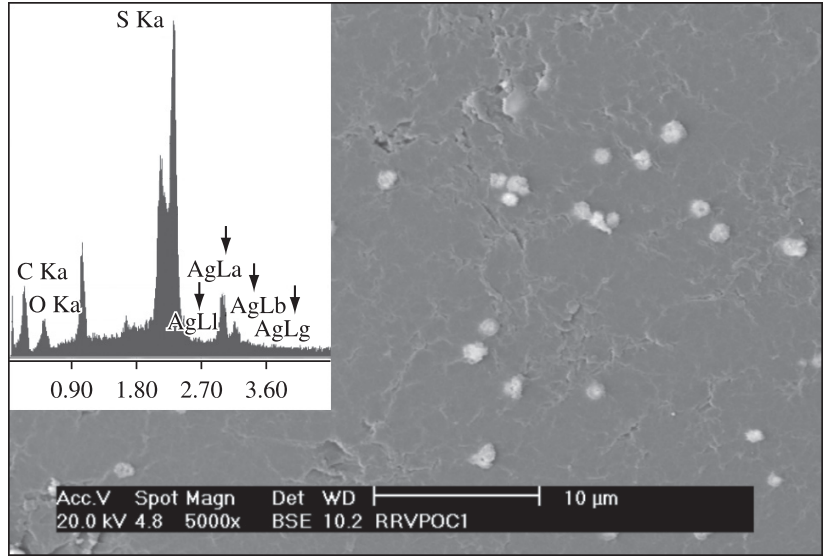

(a)

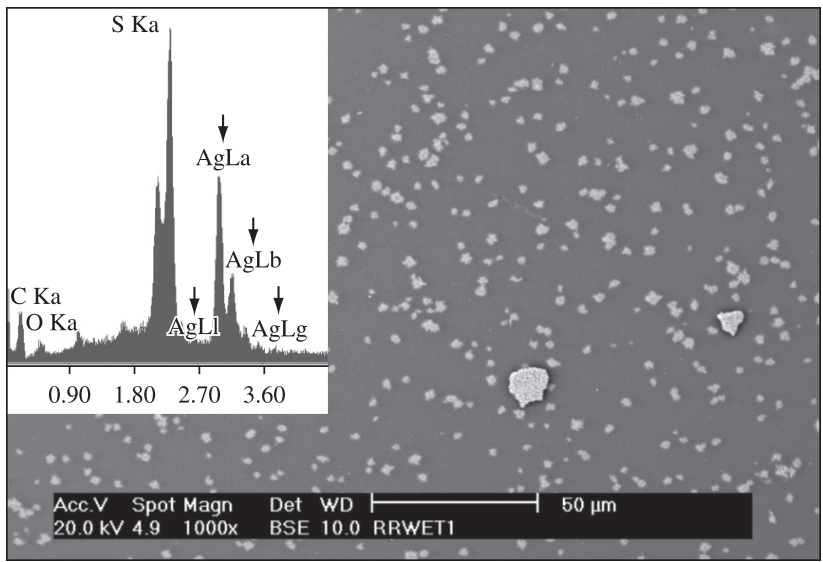

(c)

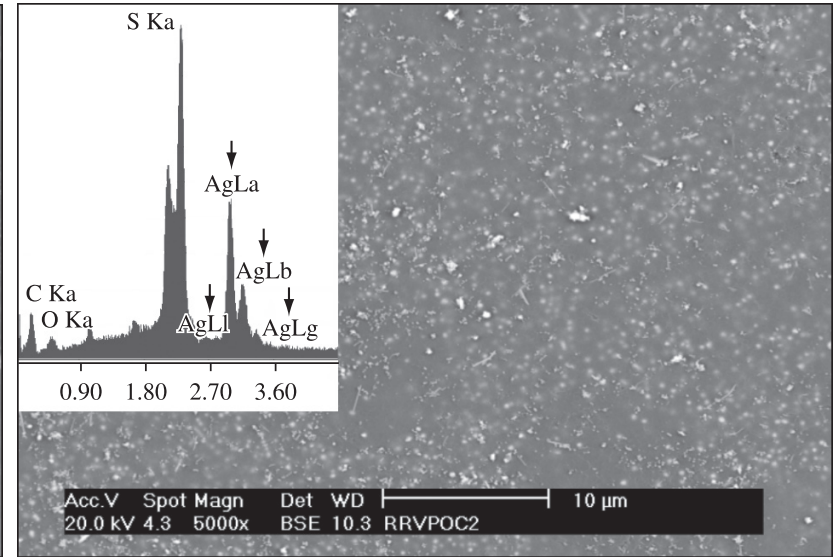

(b)

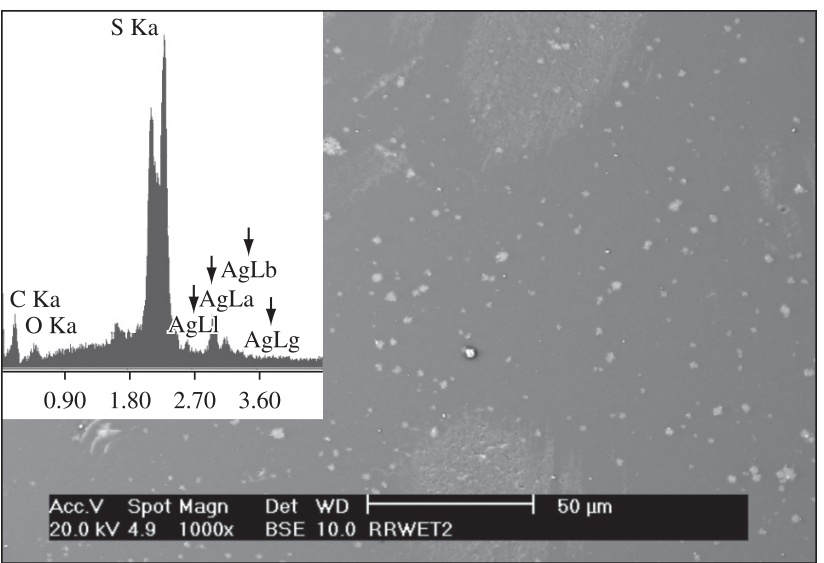

(d)

Figure 1. SEM and EDS results of the impregnated silver nanoparticles in the different final composites: a) VPOC1; b) VPOC2; c) WET1; d) WET2.<smiles>O=S(=O)(O)C1CC(O)C(O)C(O)C(O)C(O)C1O</smiles>

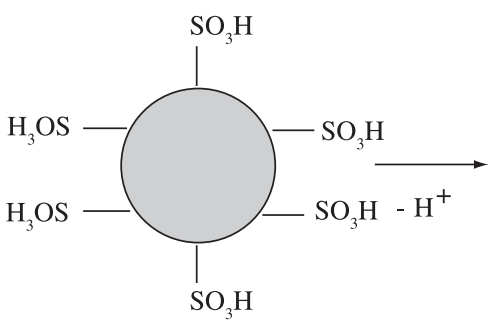

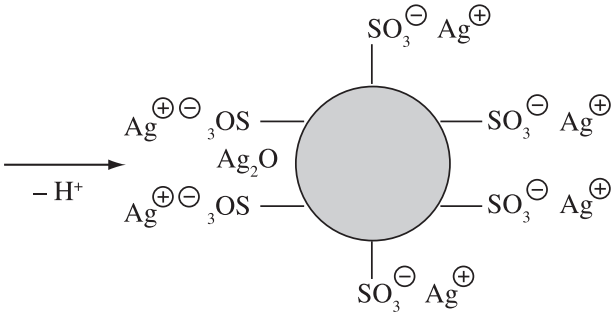

(a)

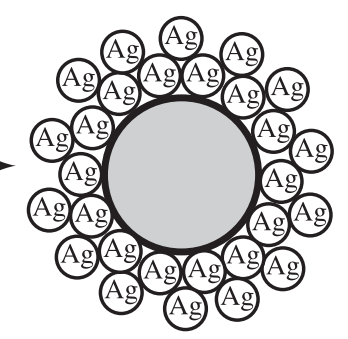

.
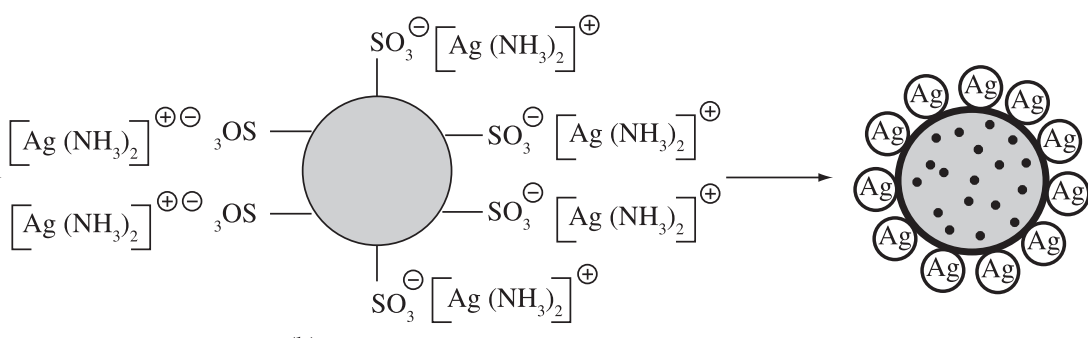

(b)

Figure 2. a) Formation of silver nanoparticles in $\mathrm{NaOH}$ presence; b) formation of silver nanoparticles in $\mathrm{NH}_{4} \mathrm{OH}$ presence. 
Table 2. Antimicrobial activity of the copolymers before and after the silver addition.

\begin{tabular}{lc}
\hline \multicolumn{1}{c}{ Copolymers } & Antimicrobial activity $(\%)^{\mathbf{a}}$ \\
\hline Lewati ${ }^{\circledR}$ VPOC1800 & 0 \\
VPOC1 & 54 \\
VPOC2 & 100 \\
Amberlyst & 15WET \\
WET1 & 0 \\
WET2 & 91 \\
\hline
\end{tabular}

Relative standard deviation $=5 \%$ UFC; significant bactericidal action $>14 \%$; a) average of concentrations from $10^{3}$ to $10^{7}$.

\section{Conclusion}

The different methods used to obtain copolymers containing silver nanoparticles were successful. The $\mathrm{NH}_{4} \mathrm{OH}$ presence had an important role on the formation of smaller silver particles due to a possible silver complex formation during the reduction reaction. The bactericide effect is related to the interaction between silver and E. coli. Factors such as high surface area and a homogeneous distribution of the particles favor this interface. The absence of reduction in viable counts in the control groups demonstrates that the antibacterial effect is only due to the silver nanoparticles, not the copolymer itself.

\section{Acknowledgements}

We thank to CNPq (Process 473687/2008-9), CAPES (Process 23038.019135/2009-63) and FAPERJ (Process APQ1 E-26/171.289/2006) for financial support. We also express our thanks to Bayer and Rohm and Haas for donating the resins.

\section{References}

1. Ashbol, N. J. - Toxicology, 198, p.229-238 (2004).

2. Koneman, E. W.; Allen, S. D.; Janda, W. M.; Schreckenberger, P. C. \& Winn, W. C. - "Color Atlas and Textbook of Diagnostic Microbiology", J. B. Lippincott, Philadelphia (1997).
3. ESCWA - Economic and Social Commission for Western Asia. "WasteWater Treatment Technologies: A General Review" http://www.escwa. un.org/information/publications/edit/upload/sdpd-03-6.pdf, accessed in: December 2009.

4. Timms, S.; Colquhoun, K. O. \& Fricker, C. J. - Microbiol. Methods., 26, p.125-132 (1996).

5. Eby, D. M.; Schaeublin, N.; Farrington, K.; Hussain, S. M. \& Johnson, G. R. - ACS Nano., 3, p.984-994 (2009).

6. Gupta, P.; Bajpai, M. \& Bajpai, S. K. J. - Cotton Sci, 12, p.280-286 (2008).

7. Matijevic, E. - "Medical Applications of Colloids", Springer, New York (2008).

8. Souza, M. A.; Pessan, L. A. \& Rodolfo Jr, A. - Polímeros, 16, p.257-262 (2006).

9. Guimarães, M. A.; Tibana, A.; Nunes, M. P. \& Santos, K. R. N. - Braz. J. Microbiol, 31, (2000).

10. Jandrey, A. C.; Santa Maria L. C.; Aguiar, A. P.; Aguiar, M. R. M. P.; Mazzei, J. L. \& Felzenszwalb, I. - J. Appl. Polym. Sci., 93, p.972-976 (2004).

11. Li, Y.; Leung, P.; Yao, L.; Song, Q. W. \& Newton, E. - J. Hosp. Infect., 62, p.58-63 (2006).

12. Glaser, A. N. - "High-Yield Biostatistics", J. B. Lippincott, Philadelphia (2005).

13. Arteca, G. A. \& Allen, D. R. V. - J. Mol. Graphics, 14, p.235-242 (1996).

14. Cai, W.; Zhang, 1.; Zhong, H.; He, G. - J. Mater. Res., 13, p.2888-2895 (1998).

15. Guo, Y. G.; Hu, J. S.; Liang, H. P.; Wan, L. W. \& Bai, C. L. - Chem. Mater., 15, p.4332-4336 (2003).

16. Chan, W. T. \& Fournier, R. - Chem. Phys. Lett, 315, p.257-265 (1999).

Enviado: $24 / 01 / 10$

Reenviado: $30 / 03 / 10$

Aceito: 05/04/10

DOI: $10.1590 / \mathrm{S} 0104-14282010005000028$ 